\title{
Establishment of an Innovative Telehealth Speech and Language Therapy Placement as a Rapid Response to COVID-19: Sharing the Learning
}

\author{
*Rena Lyons ${ }^{a}$, Laura Loftus ${ }^{a}$, Margaret Rodden ${ }^{b}$, Siobhan Ward Lynch ${ }^{c}$, Sonya \\ Gaffney $^{d}$, \& Brid McAndrew ${ }^{d}$ \\ a: NUI Galway, Ireland; b: Health Services Executive, Galway, Ireland; c: Health Services \\ Executive, Donegal, Ireland; d: Voices for Down Syndrome Galway, Ireland.
}

\begin{abstract}
The aim of this evaluation was to explore practice educators' and speech and language therapy (SLT) students' experiences of a rapid response telehealth placement in response to the COVID-19 pandemic in order to inform quality improvement. In March 2020, public health restrictions were imposed across Ireland in efforts to 'flatten the curve' in response to the COVID-19 pandemic. All placements were cancelled. According to an Irish Association of Speech and Language Therapists survey in April 2020, 47\% of SLTs were redeployed to swabbing and contact tracing roles, and many remain redeployed seven months later. This redeployment, along with strict public health measures in clinical sites, significantly reduced the availability of clinical placements. A rapid response was required to enable students to develop clinical competencies. Although telehealth has been used to deliver speech and language therapy in other countries, it had not been used routinely in service provision in Ireland. In this article, we outline how we built on existing partnerships with practice educators, both on- and off-site, to design a much-needed telehealth placement. We explored educators' and students' experiences using an online focus group and online survey respectively. The evaluations of practice educators were positive in that despite their initial apprehension, they reported that this placement provided valuable learning opportunities for students while also providing benefits for clients. They also reported some technological and sustainability challenges. The students also evaluated this placement positively with $83.3 \%$ of respondents rating the placement as 'excellent 'and $16.7 \%$ rating it as 'good'. All stakeholders valued this learning experience.
\end{abstract}

Keywords: clinical placements; COVID-19; rapid response; telehealth

*Corresponding Author: Rena Lyons, Discipline of Speech and Language Therapy, School of Health Sciences, College of Medicine, Nursing and Health Sciences, NUI Galway, Ireland Email: rena.lyons@nuigalway.ie

Journal URL: https://publications.coventry.ac.uk/index.php/pblh

Lyons, R., Loftus, L., Rodden, M. Ward Lynch, S., Gaffney, S., \& McAndrew, B. (2021). Establishment of an innovative telehealth speech and language therapy placement as a rapid response to COVID-19: Sharing the Learning. International Journal of Practice-based Learning in Health and Social Care, 9(2), 11-20. DOI 10.18552/ijpblhsc.v9i2.738

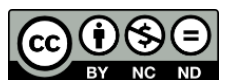
$\&$ Brid McAndrew. This Open Access article is distributed under the terms of the Creative Commons Attribution Attribution-Non-Commercial No Derivatives 4.0 International License (https://creativecommons.org/licenses/by-nc-nd/4.0/), which permits unrestricted non-commercial use, distribution, and reproduction in any medium, provided the original work is properly cited and is unaltered. 


\section{Background literature}

Clinical placements provide practical opportunities for students to apply theory to practice and they facilitate socialisation into the profession (Quigley et al., 2020). Speech and language therapy (SLT) students are required to complete a minimum of 450 hours of clinical placements before they can qualify and are eligible to register. Clinical placement capacity had always been challenging and was further exacerbated by the declaration of a COVID-19 pandemic on $11^{\text {th }}$ March 2020 (World Health Organisation, 2020a). On 12 ${ }^{\text {th }}$ March 2020, the highest level of public health restrictions were imposed in efforts to 'flatten the curve' and all clinical placements were cancelled. Although public health officials allowed the resumption of clinical placements in June 2020 (with enhanced infection control measures), placement capacity continued to be significantly reduced. Up to $47 \%$ of speech and language therapists were redeployed to testing and contact tracing roles from March - December 2020 (Irish Association of Speech and Language Therapists, 2020). This redeployment, along with strict public health measures in clinical sites, significantly reduced and continues to reduce the availability of clinical placements. In a joint call for clinical placements from the four universities offering speech and language therapy programmes in Ireland, 19\% of placements were secured. The acute shortage led to the possibility that some students would be unable graduate on time which in turn had implications for the workforce. As a rapid response to this placement crisis, we designed and implemented an innovative telehealth clinic to provide undergraduate speech and language therapy students with clinical learning opportunities. In this article, we share the learning about our experiences.

Although a range of terms can be used, we use the term telehealth to refer to "the application of telecommunications technology to deliver clinical services at a distance by linking clinician to client, caregiver, or any person(s) responsible for delivering care to the client, for the purposes of assessment, intervention, consultation and/or supervision." (Speech Pathology Australia, 2014, p. 4). Virtual clinical consultations increased significantly as a way of delivering services safely during the pandemic (Greenhalgh et al., 2020). High satisfaction ratings in relation to telehealth have been reported from both clients and practitioners (Greenhalgh et al., 2020; Tenforde et al., 2020). There is also evidence to suggest that telehealth can be used in clinical education. For example, Twogood et al. (2020) pivoted to a telehealth placement for physiotherapy students when faced with a shortage of placements due to the pandemic. The telehealth placement enabled clients who were shielding or self-isolating to access a service and it also enabled students with pre-existing health conditions to complete the placement. Likewise, Serwe et al. (2020) in their scoping review of student experiences of telehealth, found that high levels of student satisfaction related to this type of placement with a range of positive learning outcomes for students. Some of the challenges identified included issues related to technology and difficulty establishing rapport with clients in telehealth sessions. A further advantage of telehealth placements was the possibility of providing remote supervision. These findings were consistent with high ratings of satisfaction of telehealth placements among speech and language therapy students (Carlin et al., 2012; Carlin et al. 2013).

\section{The design of a rapid response telehealth placement}

Although rarely used in Ireland, telehealth is not new and has been used to deliver speech and language therapy in some countries (Regina Molini-Avejona et al., 2015). In response to the pandemic, the Health Services Executive (HSE) COVID-19 Telehealth Steering Committee (2020) developed resources and guidelines to support the implementation of telehealth across the health services. They recommended use of Attend Anywhere ${ }^{\circledR}$ which is a clinical video consultation platform (https://www.ehealthireland.ie/national-virtual-health-team/attend-anywhere/). However, the implementation of telehealth in speech and language therapy was slow because of the extent of redeployment. Given the crisis with placement capacity, we turned our attention to designing an innovative telehealth placement in April 2020 with a view to implementation in September 2020. We drew on professional body guidance about telehealth placements (American Speech-Language-Hearing Association, 2020; Irish Association of Speech and Language Therapists, 2020; Speech Pathology Australia, 2020). We learned that students could be supervised remotely, that the supervisor should be available $100 \%$ of the time, and that at a minimum the supervision should be synchronous for at least part of the placement. Given that a telehealth placement was the only viable safe option at that time, we engaged with both professional and regulatory bodies. 
We were fortunate to have an on-site university-based clinic where the placement could be delivered. This clinic is run in partnership with the local primary care service and a parent-run service called Voices for Down Syndrome Galway, which employs two speech and language therapists. We prioritised the fourth year cohort given that their third year placement had been cancelled and there were no placements available for them. We drew on existing strong partnerships to design and implement this innovative placement. The team included a university-based Practice Education Coordinator (the second author who lead the project), two Practice Tutors who had a specific brief to support practice education (one was based in the on-site clinic and the other was based at a geographically remote site), and two therapists who worked with Voices for Down Syndrome Galway. During the preparation phase, the team upskilled on delivery of telehealth through attendance at national and international webinars as well as consultation with colleagues in Australia who were already implementing telehealth placements. The team learned about the features of the online platforms and ways in which speech and language therapy could be delivered online. They also learned about specific aspects of student supervision online e.g., the logistics of remote supervision, negotiating ways of providing feedback during and after sessions, and the practicalities of conducting pre- and post-briefing sessions online. The educators working with Voices for Down Syndrome Galway already had five months experience of using telehealth. They offered a hybrid placement with some telehealth and some in-person placements.

In September 2020, twenty-six final year students commenced a novel 44-day telehealth placement which ran across 10 weeks. The placement coincided with a second surge in infection rates and the implementation of the highest level of restrictions in October/November 2020. One of the infection control measures was that students were divided into bubbles of eight, based on their friendships and living arrangements. They were allocated to one of five educators and were assigned their own desks in different rooms in the on-site clinic to minimise risks. The early part of the placement involved familiarisation and practice with the platforms Attend Anywhere, clinical video consultation platform, and Zoom ${ }^{\circledR}$ a videoconferencing platform that has features such as online meetings and secure recording of sessions (Zoom Video Communications Inc., 2016). Given that the roll out of Attend Anywhere was still in its infancy, in the early part of the placement, only educators had access to licenses which meant that they had to schedule appointments. This was subsequently resolved and licenses were later issued to students. One of the tutors had a caseload of adults with voice disorders who were deemed suitable for telehealth given that many were shielding. Local public service therapists were requested to refer clients to the telehealth clinic. The students then prioritised these cases and made initial contact with the clients to set up appointments. Much of the early success in transitioning clients from traditional in-person appointments to telehealth was attributed to students supporting clients with setting up the telehealth consultations.

With regard to supervision, protocols were put in place to ensure that there was mutual understanding of the supervisory process. The supervision process included scheduled pre- and post-session briefings, review of session plans, observing online sessions, as well as provision of constructive educator and peer feedback. The practice education team provided e-supervision, as described by Carlin et al. (2012), to provide synchronous supervision which enabled supervision from a geographically remote location and provided a time-efficient way to supervise multiple students in a safe way. Students' clinical competencies were assessed at the end of the placement. The aim of this evaluation was to explore practice educators' and students' experiences of implementing a rapid response telehealth placement in response to the COVID-19 pandemic to inform quality improvement.

\section{Method}

Concurrent mixed methods were used in this evaluation; a focus group was used to explore the practice educators' experience of implementing a rapid response telehealth placement and an online survey was used to explore the students' experiences. Given that it was an evaluation, ethical approval was not deemed necessary. Nonetheless, the participants were provided with information about the purpose of the evaluation and were assured that participation was voluntary and that their responses would be treated confidentially. Informed consent was sought from all participants. 
The five practice educators who were involved in the design and delivery of the placement participated. All 26 fourth year students were invited and 18 participated, representing a $69 \%$ response rate. Sixty-one percent of participants received supervision from educators based in the on-site clinic, 33\% had a hybrid placement, and $5 \%$ had a remote telehealth placement.

We used an online focus group to explore the practice educators' experiences of telehealth that was facilitated by the first author using the platform Zoom®. We selected focus groups rather than individual interviews because the educators already knew each other well and had all shared a recent experience of implementing a telehealth placement. "The point of a focus group is to take advantage of the interaction between group members which may produce information different in certain respects from that produced with each group member [alone]" (Howitt, 2013, p. 93). A topic guide was sent to participants in advance and included five areas i.e., expectations, strengths, challenges, opportunities, threats and recommendations. The discussion was digitally recorded, with consent, and was transcribed using the live transcript feature on Zoom®.

The transcript was reviewed for accuracy by the first author. Pseudonyms were used to protect the participants' identities. These data were analysed by the first author using content analysis. Content analysis is "a systematic and objective means of describing and quantifying phenomena" (Elo \& Kyngäs, 2008, p. 108). The outcome of the analysis was the identification of overall categories describing the phenomenon of interest. In the first instance, a deductive approach was used where the focus groups topics served as categories (parent nodes) in NVivo12 (QSR International Pty Ltd., 2018). Within each category, data were inductively coded to subcategories (child nodes). Eighty-two of these subcategories were identified which were reviewed, clustered into coherent meaning-based categories, and were then re-named as overall categories. The participants were invited to review the content analysis to ensure that it reflected their experiences.

We considered methods that could be used to explore the students' experiences. Given the short timeline and desire to capture the views of as many students as possible, we decided to use an online survey. We had consulted with Dr. Jemma Skeat, University of Melbourne, who had also implemented a rapid response telehealth clinical placement. We adapted an online survey that she had designed, with permission, to explore the students' experiences. There were nine closed questions, which respondents answered using a Likert scale, and eight open-ended questions. The students were assured that their responses would be treated confidentially. Descriptive statistics were used to analyse the closed questions and content analysis was also used to analyse the data generated in the open-ended questions.

\section{Results}

\section{Practice Educators' Experiences}

Four overall categories were identified: initial apprehension; advantages for clients; facilitating student learning; technology and sustainability challenges.

\section{Initial apprehension}

Although three practice educators already had 3-5 months experience using telehealth with clients, all five reported that they were apprehensive about implementing this new telehealth placement. Educators felt a burden of responsibility to deliver on this novel placement for students which they were designing and implementing from scratch. There were fears about the availability of sufficient numbers of clients to make the placement viable, as well as concerns about lack of knowledge and confidence with the technology.

Two participants reported hearing negative views about telehealth. All practice educators reported that their initial feelings of apprehension dissipated when they started the placement.

All participants encouraged others to have courage and give it a go. They talked about the importance of finding a supportive network, adopting a solution-focused approach, and learning as you go. 


\section{Advantages for clients}

The practice educators reported that telehealth worked well for some clients and was challenging with others e.g., children with complex needs. Telehealth enabled the safe continuity in service provision even through a six-week lockdown. Telehealth provided flexibility, saved time and for some clients, it enhanced attendance and enabled increased dosage.

\section{Facilitating student learning}

All educators reported that most clinical competencies could be attained on this placement. Where competencies were more challenging to attain (e.g., using formal assessment and liaising with members of the multidisciplinary team), the educators planned specific activities to enable students to develop these competencies. Furthermore, they reported that the challenges of conducting formal assessments online required the students to hone their informal assessment skills e.g., language sampling, as well as questioning and listening skills.

Although it was challenging to work directly with some preschool children online, the educators reported that this placement provided opportunities for students to hone their parent coaching skills. Given that this placement also involved the establishment of a new telehealth service, students had a unique opportunity to be involved in the setting-up process; they made initial contact with clients; scheduled appointments; supported clients with access; planned and managed resources and provided an episode of care.

At the end of the placement, there was a recruitment campaign for posts in the health service and students were eligible to apply. The practice educators reported that the students' experience of telehealth provided them with many experiences that they could draw on when completing the application form. The educators reported that this placement prepared students for work in a service where virtual consultations will be more commonplace.

In contrast with the educators' feelings of apprehension about technology, the practice educators reported that many students were already confident and competent with technology and were able to design creative and interesting resources for online sessions. In this way, the placement provided opportunities for reciprocal learning where the students and practice educators learned with and from each other.

Furthermore, one participant reported that she felt that students had fewer financial concerns during the telehealth placement because there were no additional costs related to travel and accommodation normally incurred in attending clinical placements remote from the university. She felt that the telehealth placement reduced this financial burden which in turn eased this stress for students and enabled them to focus more on their learning.

Regarding the model of supervision, the educators reported that the ratio of one educator to 6-8 students also facilitated peer-learning with opportunities for students to learn with and from each other. In the prebriefing sessions, there were agreements about how feedback would be managed within the online sessions. When the student took the lead in delivering the online session, the educator was in the background. This meant that the student carried additional responsibility in delivering the session because they were seen by clients as the 'therapist'.

\section{Technology and sustainability challenges}

Some clients had no computers and there were connectivity difficulties on both sides which impacted on access. Students worked with clients to find solutions. For example, clients with voice disorders accessed sessions on their telephones in their cars. There were some reservations about the limited functionality available on Attend Anywhere ${ }^{\circledR}$ compared with other platforms.

Although all practice educators were positive about this placement, there were concerns about the longerterm sustainability where involvement from a wider range of practice educators would be required. Two participants had concerns that therapists may not offer telehealth placements because they may not feel confident or competent with this form of service delivery. There were concerns that telehealth may not be 
sufficiently bedded down in practice which could impact on its sustainability. There may also be infrastructural challenges e.g., access to computers and space especially in the context of shared offices.

\section{Student's experiences of telehealth placement}

When asked how they would rate the placement overall, $83.3 \%$ of respondents rated the placement as 'excellent' and $16.7 \%$ rated it as 'good'. Students also rated a range of aspects of the placement positively (see Figure 1).

\section{Figure 1}

\section{Students' evaluation of telehealth placement}

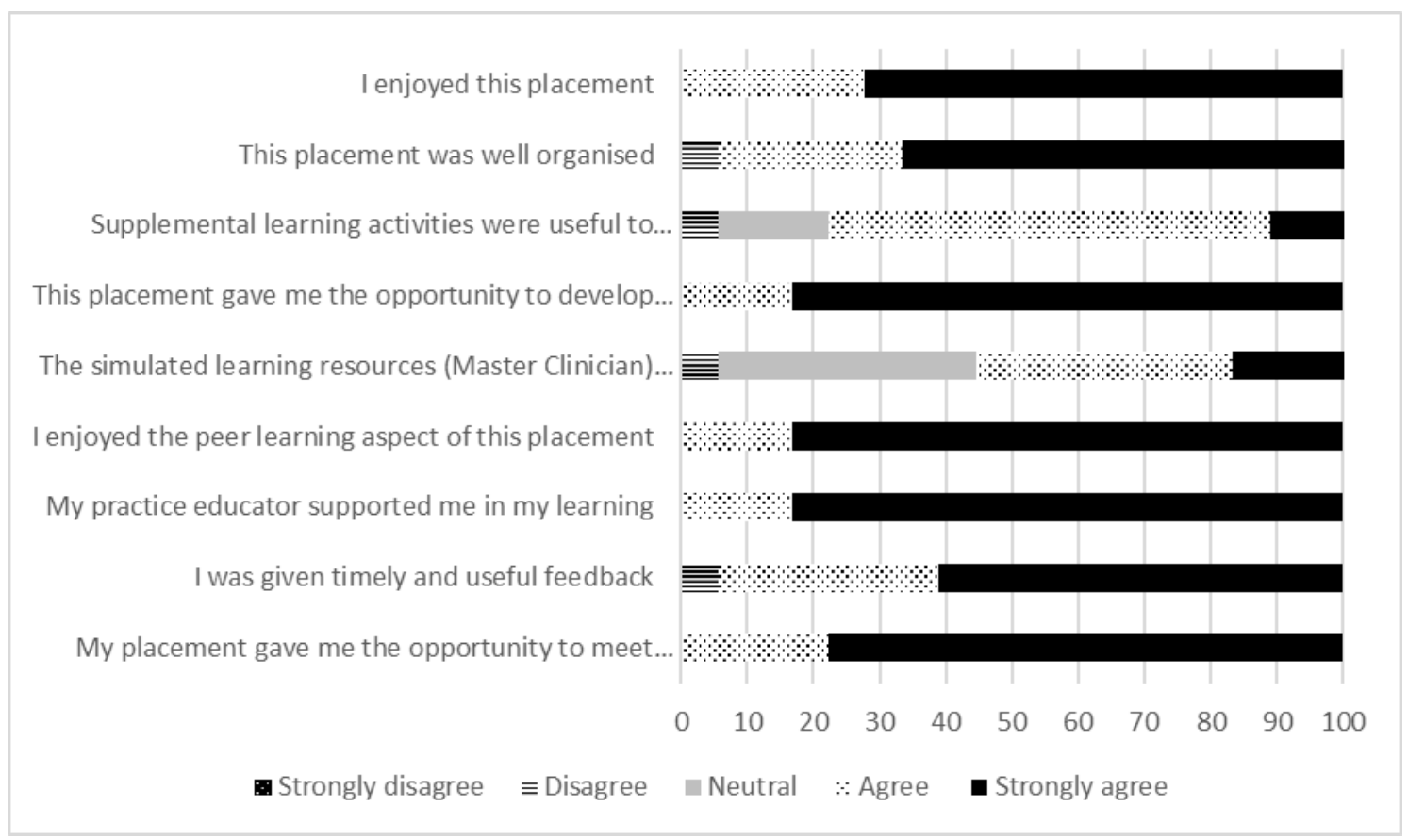

The aspects of the placement which were most highly rated were: peer learning (83.3\% strongly agreed); opportunities to develop clinical competencies (83.3\% strongly agreed); and support from their practice educators ( $83.3 \%$ strongly agreed). Seventy-eight percent strongly agreed that the placement provided opportunities to meet some learning goals. Seventy-two percent strongly agreed that they had enjoyed the placement. There were mixed views about whether simulated learning materials contributed to their learning (44.5\% were neutral or disagreed; $55.5 \%$ agreed or strongly agreed). They were more positive about the benefits of supplemental learning activities (e.g., developing video podcasts, peer simulations, resource development) (83\% agreed or strongly agreed). Ninety-four percent strongly agreed or agreed that they received timely and useful feedback.

The responses to the open-ended questions corroborated with the responses in the survey and the views of the practice educators. The aspects of the placement that students enjoyed and helped their learning included: support from educators (72\%); feeling confident using telehealth and prepared for workforce $(55 \%)$; setting up a new service (50\%); working with a range of clients $(50 \%)$; learning from and with peers $(50 \%)$; taking responsibility of all aspects of client management (47\%); and some reported that this placement was less stressful than traditional placements $(12 \%)$. The aspects of the placement that students enjoyed least were connectivity and practical difficulties (33\%), workload management (22\%) and challenges with supervision (11\%). When asked about recommendations for future telehealth placements, the following suggestions were provided: address connectivity issues in the on-site clinic (27\%); have more resources available for telehealth that can be shared $(27 \%)$; more workshops and practice sessions at the beginning (27\%); have Attend Anywhere® licences available at the beginning of the placement 
$(27 \%)$; have a case note system in place early in the placement (18\%); more regular supervision (9\%) and provide headsets $(9 \%)$.

\section{Discussion}

The aim of this evaluation was to explore practice educators' and students' experiences of a rapid response telehealth placement to inform quality improvement. At the time of design and implementation, no placements were available, and a telehealth placement was the only viable and safe option. Both educators and students evaluated this innovative placement positively, with considerable overlap between their experiences.

The positive evaluations of this telehealth placement are consistent with high ratings of satisfaction reported in other studies (Carlin et al., 2012; Serwe et al., 2020). The majority of students had high satisfaction ratings for the supervision and support they received. We agree with Carlin et al., (2012) that e-supervision offers an effective and efficient means to provide placements that meet the requirements of accreditation bodies and universities. Our findings also support the view of Carlin et al. (2012) that telehealth placements provide opportunities for students to work with a range of client groups across geographically remote sites, without compromising the quality of supervision. One of the aspects of the placement that enhanced the students' learning was the unique opportunity to be involved in the establishment of a new service. This experience enabled them to become independent, competent and confident. This finding is consistent with that of Carlin et al., (2012) who also found that students perceived that the telehealth placement improved their independence because they were primarily responsible for carrying out all aspects of the job under supervision. Students took responsibility for delivering the sessions, with the supervisor in the background, and in the responses to the open-ended questions, 47\% reported that this enhanced their learning. Carlin et al., (2013) also reported that students sometimes forgot that they were being observed in online sessions (in contrast with a supervisor sitting in the room) which enabled them to focus on the client and the service rather than the supervisor. It is also worth noting that the students in this evaluation were final year students so working towards independence was an appropriate goal. These final year students had already attained some foundation clinical competencies. Students in earlier years in the programme would require additional support and supervision because they would be attaining clinical competencies as well as learning about service delivery using online platforms. In contrast with the findings reported by Serwe et al., (2020), the students perceived that they could develop rapport with clients which may be a result of seeing them over a number of weeks.

This placement provided opportunities for students to hone their informal assessment skills. Although it is possible to conduct some standardised tests online, this option was not available for this placement. While there are advantages to standardised tests, there are also limitations regarding ecological validity. Language sampling enables the assessment of children's natural linguistic behaviour, but surveys show that language sampling is not used routinely in clinical practice (Pavelko et al., 2016). This placement provided students with opportunities to hone their language sampling skills and potentially enhanced the likelihood that they may use language sampling in the future. Furthermore, this placement provided students with opportunities to develop their competencies regarding parent coaching and involving others in the intervention.

Given that the telehealth placement was new for all, there was an ethos of learning with and from each other. Students reported that they found supplemental activities specific to telehealth more useful than other activities such as simulated cases, and that they would like more resources for telehealth that could be shared, as well as more workshops and practice sessions. Serwe et al., (2020) argued that while telehealth education can include a range of methods such as didactic, simulated, and experiential learning components, more research is required to identify optimal educational delivery models. Students also valued peer support which is also consistent with the literature (Stenberg \& Carlson, 2015). Further research is required to evaluate student outcomes comparing outcomes from telehealth and traditional placements. 
Although the evaluation of this rapid response telehealth placement was positive, we are also aware of challenges. Telehealth may not be a suitable service delivery for all clients. For example, it may be challenging to keep young children engaged in tasks online and some clients, and some clients, including the students in this evaluation, may prefer in-person service delivery. Although the students in this evaluation reported that they could develop rapport with clients online, there may be challenges regarding interpersonal communication in online service delivery. For example, Overby (2018) found that developing rapport with clients online may be challenging due to lack of physical proximity and it may be difficult to demonstrate enthusiasm with facial cues alone. Furthermore, students also missed out on planned and incidental meetings with other members of the multidisciplinary team that take place during in-person clinical placements. To address this challenge, meetings were arranged to involve others. A further issue was that students did not have access to clients' clinical files, though procedures for record keeping and writing case notes were developed during the placement. Both students and educators also reported some technological and connectivity challenges, which have been reported in the literature (Serwe et al., 2020).

\section{Conclusion}

As we write this article in January 2021, Ireland is experiencing a third surge of COVID-19 with the highest daily number of new confirmed cases in the world for every million people. Furthermore, two new, more transmissible variants of the virus are now in Ireland and the highest level of restrictions are in place again. Although public health officials are permitting clinical placements, the placement landscape remains very challenging. As we move forward, telehealth placements, along with other approaches such as simulation (Hill et al., 2020), continue to provide valuable opportunities for students to develop competencies. Furthermore, it is important that both staff and students are protected, given the current high rates of transmission of infection, and we also look forward with the hope that comes with the vaccines.

Although the team were apprehensive about this placement and could have tried to get it to be perfect before starting, we were inspired by the comments of Dr. Mike Ryan (World Health Organisation, 2020b) who argued that "If you need to be right before you move - you will never win. Perfection is the enemy of the good when it comes to emergency management" (p. 9). We were also fortunate that we had a resilient cohort of students who embraced the placement. Given that telehealth is likely to be part of future service delivery, we agree with Twogood et al. (2020, p.6) that the competencies learned by the students "are likely to form part of the future of healthcare delivery and this model provides a unique learning opportunity for exposure to such skills early in the student's careers".

\section{Acknowledgements}

We would like to thank our students who embraced this innovative telehealth placement. We would like to thank the Buildings Office, NUI Galway, for their support in enabling access to the building at a time when most university buildings were closed because of the pandemic. They were very helpful in supporting us to ensure that the on-site clinic space was safe. We would also like to thank the Health Services Executive (HSE) for their support. In particular to Marie Prendergast (HSE) for her assistance accessing licenses for the Attend Anywhere platform. We would like to thank Edel Dunphy, Professional Development Manager, Irish Association of Speech and Language Therapists, for her role in organising and providing webinars to support therapists to use telehealth. Special thanks also to Dr. Jemma Skeat, University of Melbourne, Australia, for so generously sharing her experiences of telehealth placements.

\section{ORCID}

Rena Lyons:

https://orcid.org/0000-0001-7294-9707

Laura Loftus:

https://orcid.org/0000-0002-3554-2489

Margaret Rodden:

https://orcid.org/0000-0003-3952-4162 
Siobhan Ward Lynch:

Sonya Gaffney:

Brid McAndrew: https://orcid.org/0000-0003-4025-5537

https://orcid.org/0000-0001-8029-2872

https://orcid.org/0000-0001-9899-3968

\section{References}

American Speech-Language-Hearing Association. (2020). COVID-19: Guidance for graduate programs, students, and clinical fellows. https://www.asha.org/Certification/COVID-19-Guidance-From$\mathrm{CFCCl}$

Carlin, C. H., Boarman, K., Carlin, E., \& Inselmann, K. (2013). The use of E-supervision to support speech-language pathology graduate students during student teaching practica. International Journal of Telerehabilitation, 5(2), 21-31. https://doi.org/10.5195/ijt.2013.6128

Carlin, C. H., Milam, J. L., Carlin, E. L., \& Owen, A. (2012). Promising practices in e-supervision: exploring graduate speech-language pathology interns' perceptions. International Journal of Telerehabilitation, 4(2), 25-38. https://doi.org/10.5195/ijt.2012.6103

Elo, S., \& Kyngäs, H. (2008). The qualitative content analysis process. Journal of Advanced Nursing, 62(1), 107-115. https://doi.org/10.1111/j.1365-2648.2007.04569.x

Greenhalgh, T., Wherton, J., Shaw, S., \& Morrison, C. (2020). Video consultations for COVID-19. BMJ, 368, m998. https://doi.org/10.1136/bmj.m998

Health Service Executive (HSE) COVID-19 Telehealth Steering Committee. (2020). Virtual health. https://healthservice.hse.ie/staff/coronavirus/working-from-home/virtual-health/virtualhealth.html

Hill, A. E., Ward, E., Heard, R., McAllister, S., McCabe, P., Penman, A., Caird, E., Aldridge, D., Baldac, S., Cardell, E., Davenport, R., Davidson, B., Hewat, S., Howells, S., Purcell, A., \& Walters, J. (2020). Simulation can replace part of speech-language pathology placement time: A randomised controlled trial. International Journal of Speech-Language Pathology, 23(1), 92102. https://doi.org/10.1080/17549507.2020.1722238

Howitt, D. (2013). Introduction to qualitative methods in psychology (2nd ed.). Pearson.

Irish Association of Speech and Language Therapists. (2020). Supporting student speech and language therapy placements in the context of COVID-19: A practice educator guide to a blended approach.

https://www.iaslt.ie/attachments/Supporting\%20Student $\% 20$ Speech $\% 20$ and $\% 20$ Language $\% 20 \mathrm{~T}$ herapy\%20Placements\%20in\%20the\%20Context\%20of\%20COVID-19.pdf

Overby, M. S. (2018). Stakeholders' qualitative perspectives of effective telepractice pedagogy in speech-language pathology. International Journal of Language \& Communication Disorders, 53(1), 101-112. https://doi.org/10.1111/1460-6984.12329

Pavelko, S. L., Owens, J. R. E., Ireland, M., \& Hahs-Vaughn, D. L. (2016). Use of Language Sample Analysis by School-Based SLPs: Results of a Nationwide Survey. Language, speech \& hearing services in schools, 47(3), 246-258. https://doi.org/10.1044/2016_LSHSS-15-0044

QSR International Pty Ltd. (2018). NVivo 12 qualitative data analysis software. https://www.qsrinternational.com/nvivo-qualitative-data-analysissoftware/home?.ga=2.261609220.82128265.1628599603-767094404.1603179693

Quigley, D., Loftus, L., McGuire, A., \& O'Grady, K. (2020). An optimal environment for placement learning: listening to the voices of speech and language therapy students. International Journal of Language \& Communication Disorders, 55(4), 506-519. https://doi.org/10.1111/1460$\underline{6984.12533}$

Regina Molini-Avejonas, D., Rondon-Melo, S., de La Higuera Amato, C. A., \& Samelli, A. G. (2015). A systematic review of the use of telehealth in speech, language and hearing sciences. Journal of Telemedicine and Telecare, 21(7), 367-376. https://doi.org/10.1177\%2F1357633X15583215

Serwe, K. M., Heindel, M., Keultjes, I., Silvers, H., \& Stovich, S. (2020). Telehealth student experiences and learning: A scoping review. Journal of Occupational Therapy Education, 4(2). https://doi.org/10.26681/jote.2020.040206 
Speech Pathology Australia. (2014). Telepractice in speech pathology position statement. https://www.speechpathologyaustralia.org.au/SPAweb/Resources_for_Speech_Pathologists/Prof essional_Resources/HTML/Telepractice.aspx

Speech Pathology Australia. (2020). University programs: COVID-19 and accreditation https://www.speechpathologyaustralia.org.au/SPAweb/Resources_for_the_Public/University_Pr ograms/SPAweb/Resources for the Public/University Programs/University_Programs.aspx?hk ey=505701a1-5369-46ce-b2d8-798507c035cd

Stenberg, M., \& Carlson, E. (2015). Swedish student nurses' perception of peer learning as an educational model during clinical practice in a hospital setting — an evaluation study. BMC Nursing, 14(1), 48. https://doi.org/10.1186/s12912-015-0098-2

Tenforde, A. S., Borgstrom, H., Polich, G., Steere, H., Davis, I. S., Cotton, K., O’Donnell, M., \& Silver, J. K. (2020). Outpatient physical, occupational, and speech therapy synchronous telemedicine: A survey study of patient satisfaction with virtual visits during the COVID-19 pandemic. American Journal of Physical Medicine \& Rehabilitation, 99(11), 977-981. https://doi.org/10.1097/phm.0000000000001571

Twogood, R., Hares, E., Wyatt, M., \& Cuff, A. (2020). Rapid implementation and improvement of a virtual student placement model in response to the COVID-19 pandemic. BMJ Open Quality, 9(4), e001107. https://doi.org/10.1136/bmjoq-2020-001107

World Health Organisation. (2020a). Coronavirus disease 2019 (COVID-19) situation report - 51. https://www.who.int/docs/default-source/coronaviruse/situation-reports/20200311-sitrep-51covid-19.pdf?sfvrsn=1ba62e57_10

World Health Organisation. (2020b). COVID-19 briefing document (March 2020): Transcript. https://www.who.int/docs/default-source/coronaviruse/transcripts/who-transcript-emergenciescoronavirus-press-conference-full13mar2020848c48d2065143bd8d07a1647c863d6b.pdf?sfvrsn=23dd0b04_2

Zoom Video Communications Inc. (2016). Security guide. Zoom Video Communications.https://d24cgw3uvb9a9h.cloudfront.net/static/81625/doc/Zoom-SecurityWhite-Paper.pdf 